\author{
$n^{\circ}$ 2011-15 \\ Optimal Redistributive Taxation \\ with both Labor Supply and \\ Labor Demand Responses \\ L. JACQUET ${ }^{1}$ \\ E. LEHMANN ${ }^{2}$ \\ B. Van Der LINDEN ${ }^{3}$
}

Les documents de travail ne reflètent pas la position du CREST et n'engagent que leurs auteurs. Working papers do not reflect the position of CREST but only the views of the authors.

\footnotetext{
$1 \mathrm{NHH}$

2 CREST

3 IRES - Université Catholique de Louvain and FNRS
} 


\title{
Optimal Redistributive Taxation with both Labor Supply and Labor Demand Responses*
}

\author{
Laurence JACQUET ${ }^{\dagger}$ \\ $\mathrm{NHH}$ \\ Etienne LEHMANN $\ddagger$ \\ CREST \\ Bruno VAN DER LINDEN ${ }^{\S}$ \\ IRES - Université Catholique de Louvain and FNRS
}

May 23, 2011

\begin{abstract}
This paper characterizes the optimal redistributive tax schedule in a matching unemployment framework where (voluntary) nonparticipation and (involuntary) unemployment are endogenous. The optimal employment tax rate is given by an inverse employment elasticity rule. This rule depends on the global response of the employment rate, which depends not only on the participation (labor supply) responses, but also on the vacancy posting (labor demand) responses and on the product of these two responses. For plausible values of the parameters, our matching environment induces much lower employment tax rates than the usual competitive model with endogenous participation only.
\end{abstract}

JEL Classification: D82; H21; J64.

Keywords: Optimal taxation, Labor market frictions, Unemployment

${ }^{*}$ We thank Bas Jacobs, Guy Laroque, Jean-Marie Lozachmeur, Louis Perrault, Alfons Weichenrieder and participants at the CPEG 2010 workshop at Queens University, the Nordic Workshop on Tax Policy and Public Economics in Copenhagen, the CESifo conference on Public Sector Economics and the workshop on "Taxation and Redistribution" at Linz for helpful comments. Laurence Jacquet would like to thank financial support from the Keilhaus Minnefond. This research has been partly funded by the Belgian Program on Interuniversity Poles of Attraction (P6/07 Economic Policy and Finance in the Global Economy: Equilibrium Analysis and Social Evaluation) initiated by the Belgian State, Prime Minister's Office, Science Policy Programming.

${ }^{\dagger}$ Laurence Jacquet is also research associate at IRES and at BETA and research network fellow at CESifo. Laurence.Jacquet@nhh.no

${ }^{\ddagger}$ Etienne Lehmann is also research associate at IRES and research network fellow at IZA, IDEP and CESifo. etienne.lehmann@ensae.fr

${ }^{\S}$ Bruno Van der Linden is also research associate at ERMES- University Paris 2 and research fellow at IZA. bruno.vanderlinden@uclouvain.be. 


\section{Introduction}

This paper analyzes the optimal income tax schedule with voluntary nonparticipation and involuntary unemployment. Individuals decide whether they participate in the labor force (the extensive margin). Because of matching frictions à la Mortensen and Pissarides (1999), a participating individual may be involuntarily unemployed. The probability for a participant to be recruited is endogenous and depends on the number of vacancies firms find profitable to create (the labor demand margin). Individuals differ both in their skills and their costs of searching for a job. The skill heterogeneity implies that employed workers earn distinct wages. The cost of searching a job differs across individuals of the same skill level, which accounts for the extensive margin as in Diamond (1980), Saez (2002) or Choné and Laroque $(2005,2011)$. As the government only observes earnings, it faces a secondbest redistribution problem. This paper derives the optimal employment tax, defined as the tax the worker pays plus the welfare benefit 1

Our model encompasses the standard case with only the extensive margin. A higher level of the employment tax reduces the return of participation, thereby inducing some individuals to stay out of the labor force. The optimal employment tax is inversely related to the elasticity of the labor supply, as in the "extensive response model" of Saez (2002).

We introduce labor demand through skill-specific matching frictions à la Mortensen and Pissarides (1999). When a worker and a vacancy are randomly matched, a surplus is created. The total surplus is the difference between the overall income the worker and the employer get from the match and what they would get if their search was unsuccessful. We make the simplifying assumption that the worker and the employer receive a fixed fraction of this surplus. An increase in the employment tax reduces the total surplus, thereby both the worker's and the employer's surplus. Therefore, a rise in the employment tax decreases the net (or after-tax) wage and increases the gross (or pre-tax) wage. Employers thus find less profitable to create vacancies, which decreases the number of taxpayers: ${ }^{2}$

In the presence of both extensive supply and labor demand margins, we show that the optimal employment tax is inversely related to the global elasticity of employment. The latter is the sum of three terms: the labor supply elasticity, the labor demand elasticity with respect to the firm surplus and the product of these two elasticities. The presence of this product is explained by the fact that any labor demand response to taxation, by changing the job-finding probability, also affects the return to participation. We also

\footnotetext{
${ }^{1}$ In the literature, the employment tax is traditionally called participation tax in the absence of (involuntary) unemployment.

${ }^{2}$ These effects are standard in the matching literature. See Mortensen and Pissarides (1999), Pissarides (2000). Empirical evidence about the effects of gross wages on employment rates can be found in e.g. Kramarz and Phillipon (2001) or Beaudry, Green and Sand (2010).
} 
numerically investigate how the introduction of the labor demand response affects the optimal employment tax rate. Our matching environment induces much lower employment tax rates than the usual competitive extensive response model. However, when the Hosios (1990) condition ${ }^{3}$ holds, optimal employment tax rates are higher in magnitude when the labor demand response is higher and the labor supply response is smaller, the overall employment response to taxation remaining unchanged.

An alternative way of introducing labor demand considerations in the optimal income tax problem consists in assuming imperfect substitution between low and high-skilled labor in a competitive setting. Stiglitz (1982) shows the desirability of a negative marginal tax rate for high-skilled workers. This reduces the inequality in wage rates, thereby relaxing the relevant incentive constraint. This framework has been extended by Allen (1987) and Guesnerie and Roberts $(1984,1987)$ who show that a minimum wage cannot relax the relevant incentive constraint. In these papers, labor supply responses are concentrated along the intensive margin.

Lee and Saez (2008) consider instead a model with extensive responses. They derive an optimal tax formula in the absence of a minimum wage..$^{4}$ The labor demand elasticity does not enter their formula. We interpret this difference with our optimal tax formula as follows. In a competitive setting, wages are flexible and clear the labor markets. Hence, in the absence of participation responses, a change in the employment tax affects neither the employment level nor the gross wage. In other words, employment responses to taxation are driven only by the supply side of labor markets, the demand side inducing only changes in prices. Conversely, in our model with matching frictions and surplus sharing, a rise in the employment tax increases the gross wage even in the absence of participation response. The employment level is then affected by the response of the labor demand, which influences the equity-efficiency tradeoff.

Several papers study the optimal income tax model under search frictions on the labor market. The optimal tax in Boone and Bovenberg (2002) and in Boadway, Cuff and Marceau (2003) acts as a Pigouvian tax to correct the inefficiency that arises from the search-congestion externalities induced by matching frictions. Hungerbühler, Lehmann, Parmentier and Van der Linden (2006) and Lehmann, Parmentier and Van der Linden (2011) consider instead an environment where these externalities are perfectly internalized by the wage setting process in the no-tax economy. The role of taxation is therefore to redistribute income and not to restore efficiency. Hungerbühler and Lehmann (2009) consider both the redistributive aspects and search-congestion externalities. In all of these

\footnotetext{
${ }^{3}$ This condition on the bargaining power guarantees that the decentralized economy is efficient in the absence of taxes, despite the presence of search-congestion externalities.

${ }^{4}$ Their main formula however concerns the case with an optimally chosen minimum wage.
} 
papers except Boadway, Cuff and Marceau (2003), a rise in the marginal tax rate increases the share of the surplus that the employer receives: a higher marginal tax rate discourages workers to claim for higher wages, thereby reducing the gross wage negotiated and boosting the labor demand. In contrast, we neglect this wage moderation effect to stress the role of the labor demand responses in the optimal tax formula.

This paper is organized as follows. Section [II presents the model. Section III derives the optimal tax formula and contrasts it with the case of a competitive labor market and labor supply responses along the extensive margin. Section IV concludes.

\section{The general framework}

We consider a static model where individuals are risk-neutral and endowed with distinct skill levels denoted by $a$. The exogenous skill distribution is given by the cumulative distribution $F(a)$, defined on $\left[a_{0}, a_{1}\right]$, with $0<a_{0}<a_{1} \leq \infty$. The size of the population is normalized to 1 . Jobs are skill-specific. A worker of skill $a$ produces $a$ units of output if and only if she is employed in a type- $a$ job 5 otherwise her production is nil. This assumption of perfect segmentation is made for tractability and is more realistic than the polar one of a unique labor market for all skill levels.

At each skill level, some people choose to stay out of the labor force while some others do participate in the labor market. We integrate this feature by assuming that individuals of a given skill level differ in their cost of searching a job $\chi$. The exogenous distribution of $\chi$ conditional on skill level $a$ is described by the (conditional) c.d.f. $H(. \mid a)$. This function is defined over the support $\mathbb{R}^{+}$, is strictly positive and admits a continuous partial derivative with respect to $\chi \in \mathbb{R}^{+}$. The characteristics $a$ and $\chi$ may be distributed independently or may be correlated.

Among individuals who participate in the labor market, some fail to be recruited and become unemployed. This involuntary unemployment is due to matching frictions. The number of matches between employers and job seekers on the labor market of skill $a$ is a function denoted $M_{a}\left(V_{a}, U_{a}\right)$ of the stock of vacant posts, $V_{a}$, and the stock of job seekers, $U_{a}$, in the market (Mortensen and Pissarides 1999).

We assume that the government neither observes individuals' types $(a, \chi)$ nor the jobsearch and matching processes ${ }^{6}$ It only observes worker's gross wage $w_{a}$. Therefore, the tax level is only a function $T$ (.) of the gross wage $w$. The government is also unable to distinguish among the non-employed individuals the (involuntary) unemployed, who searched

\footnotetext{
${ }^{5}$ Allowing an agent to work in any occupation which requires a skill below her type opens the possibility of monotonicity constraints and pooling that are studied in Choné and Laroque (2011).

${ }^{6}$ In Appendix C however, we treat the case where $(a, \chi)$ is observed.
} 
for a job but failed to find one, from the voluntary non-participants. Therefore, the government is constrained to give the same level of welfare benefit $b$ to all non-employed agents. Moreover, as our model is static, the welfare benefit cannot differ by past employment histories. Finally, the government does not observe the vacancies created by the firms, so it has no specific instrument to tax or subsidize job creation. The timing of our static model is:

1. The government commits to a tax system defined as a pair $(T(), b$.$) which only$ depends on the gross wage $w$ and the welfare benefit $b$ for the non-employed.

2. For each skill level $a$, firms open vacancies. Creating a vacancy of type $a$ costs $\kappa_{a}>0$. Each type $a$-agent decides whether she participates to the labor market of type $a$.

3. Matching occurs. Once matched, the firm and the worker share the surplus by negotiating the wage.

4. Each worker of skill $a$ produces $a$ units of goods, receives a wage $w=w_{a}$ and pays taxes or receive transfers. Non-employed individuals get the welfare benefit $b$. Tax revenue also finances an exogenous amount of public expenditures $R \geq 0$. Agents consume.

\section{II.1 Participation decision}

An individual of type $(a, \chi)$ can decide to stay out of the labor force, in which case her utility equals the welfare benefit $b$. Otherwise, she participates. Then, she finds a job with an endogenous probability $\ell_{a}$ and gets a utility level equals to $w_{a}-T\left(w_{a}\right)-\chi$ or she becomes unemployed with a probability $1-\ell_{a}$ and gets a utility level equals to $b-\chi$.

To participate, an agent of type $(a, \chi)$ should expect a higher expected utility $\ell_{a}\left(w_{a}\right.$ $\left.-T\left(w_{a}\right)\right)+\left(1-\ell_{a}\right) b-\chi$ than in case of non participation, $b$. Let $\tau_{a}=T\left(w_{a}\right)+b$ denote the employment tax. We define the expected surplus of a participant of type $a$ as

$$
\Sigma_{a} \stackrel{\text { def }}{\equiv} \ell_{a} \times\left(w_{a}-T\left(w_{a}\right)-b\right)
$$

i.e. the additional income she gets if she finds a job rather than stays unemployed multiplied by the probability of employment. Any individual of skill $a$ chooses to participate if her cost $\chi$ of searching a job is lower than the surplus $\Sigma_{a}$ she expects from finding a job, i.e. $\chi \leq \Sigma_{a}$. Let $h_{a}$ denote the participation rate among individuals of skill $a$, i.e.:

$$
h_{a}=H\left(\Sigma_{a} \mid a\right) \equiv \operatorname{Pr}\left[\chi \leq \Sigma_{a} \mid a\right]
$$


The mass of participants of type $a$ equals $U_{a}=h_{a} \cdot f(a)$. We now define:

$$
\eta_{a}^{P} \stackrel{\text { def }}{\equiv} \frac{\Sigma_{a}}{H\left(\Sigma_{a} \mid a\right)} \frac{\partial H\left(\chi=\Sigma_{a} \mid a\right)}{\partial \chi}
$$

as the elasticity of the participation rate among individuals of skill $a$ with respect to the expected surplus of a participant, at $\chi=\Sigma_{a}$. The empirical literature on the participation decisions typically estimates the elasticity of participation with respect to the difference between income in employment and in unemployment, $w_{a}-\tau_{a}$. For a given employment probability $\ell_{a}, \eta_{a}^{P}$ equals this elasticity.

\section{II.2 Labor demand}

If there were no frictions, the number of matches on the labor market of skill $a$ would be determined by the short side of the market and one would get $M_{a}\left(V_{a}, U_{a}\right)=\min \left(V_{a}, U_{a}\right)$. But when job seekers and employers have to engage in a costly and time-consuming process of search to find each other, the matching function captures the technology that brings them together. The matching process is assumed not efficient hence $M_{a}\left(V_{a}, U_{a}\right)<$ $\min \left(V_{a}, U_{a}\right)$. The matching function $M_{a}\left(V_{a}, U_{a}\right)$ is twice continuously differentiable on $\mathbb{R}_{+}^{2}$, increasing and concave in both arguments, verifies $M_{a}\left(0, U_{a}\right)=M_{a}\left(V_{a}, 0\right)=0$ since matches cannot occur unless there are agents on both sides of the market and exhibits constant returns to scale. These assumptions are largely empirically supported as discussed by Petrongolo and Pissarides (2001).

Define market tightness $\theta_{a}$ as the ratio $V_{a} / U_{a}$. The probability of filling a type- $a$ vacancy equals $m_{a}\left(\theta_{a}\right) \equiv M_{a}\left(V_{a}, U_{a}\right) / V_{a}=M_{a}\left(1,1 / \theta_{a}\right)$. Due to search-matching externalities, the probability of filling decreases with the number of vacancies $\left(V_{a}\right)$ and increases with the number of job-seekers $\left(U_{a}\right)$. Since $M_{a}\left(V_{a}, U_{a}\right)$ exhibits constant returns to scale, only tightness matters and $m_{a}\left(\theta_{a}\right)$ is a decreasing function of tightness $\theta_{a}$. Symmetrically, the probability that a job-seeker finds a job is an increasing function of tightness $\theta_{a} m_{a}\left(\theta_{a}\right) \equiv M_{a}\left(V_{a}, U_{a}\right) / U_{a}=M_{a}\left(\theta_{a}, 1\right)$ with the functions $m_{a}\left(\theta_{a}\right)$ and $\theta_{a} m_{a}\left(\theta_{a}\right)$ defined from $\mathbb{R}^{+}$to $[0,1)$. Firms and individuals being atomistic, they take tightness $\theta_{a}$ as given.

When a firm creates a vacancy of type $a$, it fills it with probability $m_{a}\left(\theta_{a}\right)$. The creation of this vacancy costs $\kappa_{a}>0$ to the firm. This fixed cost includes the screening of applicants and the investment in equipments for the extra worker. The firm's expected profit is $m\left(\theta_{a}\right)\left(a-w_{a}\right)-\kappa_{a}$. For a given number of job-seekers, a rise in the number of vacancies decreases this expected profit because each vacancy is filled with a lower probability. Firms create vacancies until the free-entry condition $m_{a}\left(\theta_{a}\right)\left(a-w_{a}\right)=\kappa_{a}$ is met. This pins down the value of tightness $\theta_{a}$ as $m_{a}^{-1}\left(\kappa_{a} /\left(a-w_{a}\right)\right) .7$ We define the

\footnotetext{
${ }^{7}$ where $m_{a}^{-1}($.$) denotes the reciprocal of function \theta \mapsto m_{a}(\theta)$, holding $a$ constant.
} 
labor demand $L_{a}($.$) as the probability of finding a job \theta_{a} m_{a}\left(\theta_{a}\right)$ in which $\theta_{a}$ is given by the free-entry condition, namely:

$$
L_{a}\left(a-w_{a}\right) \stackrel{\text { def }}{\equiv} \frac{\kappa_{a}}{a-w_{a}} \times m_{a}^{-1}\left(\frac{\kappa_{a}}{a-w_{a}}\right)
$$

One has $\ell_{a}=L_{a}\left(a-w_{a}\right)$ at the equilibrium. The $L_{a}($.$) function is a reduced form$ that captures everything we need on the labor demand side. From the assumptions made on the matching function, $L_{a}($.$) is twice-continuously differentiable and admits values$ within $(0,1)$. As the wage $w_{a}$ increases, firms get lower surplus $\left(a-w_{a}\right)$ on each filled vacancy, fewer vacancies are created and tightness $\theta_{a}$ decreases. This explains why the employment probability $\ell_{a}$ decreases with the wage $w_{a}$. Moreover, due to the constantreturns-to-scale assumption, the probability of being employed depends only on skill and wage levels and not on the number of participants. If for a given wage, there are twice more participants, the free-entry condition leads to twice more vacancies, so the level of employment is twice higher and the employment probability is unaffected. This property is in accordance with the empirical evidence that the size of the labor force has no lasting effect on group-specific unemployment rates. Finally, because labor markets are perfectly segmented by skill, the probability that a participant of type $a$ finds a job depends only on the wage level $w_{a}$ and not on wages in other segments of the labor market.

We then define the elasticity of the (type- $a$ ) labor demand to the surplus of the firm $a-w_{a}$ as (see Appendix A):

$$
\eta_{a}^{D} \stackrel{\text { def }}{\equiv}\left(a-w_{a}\right) \frac{L_{a}^{\prime}\left(a-w_{a}\right)}{L_{a}\left(a-w_{a}\right)}=\frac{1-\mu_{a}\left(\theta_{a}\right)}{\mu_{a}\left(\theta_{a}\right)}>0
$$

where (4) has been used and $\mu_{a}\left(\theta_{a}\right)$ denotes the elasticity of the matching function with respect to the mass of job-seekers $U_{a}$ evaluated at $\theta_{a}=m_{a}^{-1}\left(\kappa_{a} /\left(a-w_{a}\right)\right)$. The empirical literature on labor demand is typically concerned with the elasticity of employment with respect to the level of wage. Controlling for participation decisions in our model, the latter elasticity is negative and equals $-\eta_{a}^{D} \times\left(w_{a} /\left(a-w_{a}\right)\right)$.

\section{II.3 The wage setting}

Once a firm and a worker are matched, they share the total surplus, i.e. the sum of the firm's surplus $a-w_{a}$ and of the worker's surplus $w_{a}-T\left(w_{a}\right)-b$. In the absence of an agreement, nothing is produced and the worker gets the welfare benefit $b$. The bargaining process determines how the total surplus $S_{a}=a-T\left(w_{a}\right)-b$ is shared between the worker and the firm. The result of the bargaining can be viewed as the outcome of the maximization of an objective $\Omega_{a}\left(x_{a}, y_{a}\right)$ that is increasing in the firm's $x_{a}=a-w_{a}$ and the employee's $y_{a}=w_{a}-T\left(w_{a}\right)-b$ surplus. For instance, the generalized Nash 
bargaining framework takes the form $\Omega_{a}(x, y)=x^{1-\gamma_{a}} y^{\gamma_{a}}$, where $\gamma_{a} \in(0,1)$ captures the exogenous bargaining power of workers of skill $a$. However, other expressions for $\Omega_{a}(.,$. can be considered as well. In this paper, we consider a Leontief specification $\Omega_{a}(x, y)=$ $\min \left[\frac{x}{1-\gamma_{a}}, \frac{y}{\gamma_{a}}\right]$ to avoid an effect of marginal tax rates on wages 8 This simplification enables us to clearly identify the role of the labor demand responses in the optimal tax formula. The equilibrium wage solves:

$$
w_{a}=\underset{w}{\arg \max } \min \left[\frac{a-w}{1-\gamma_{a}}, \frac{w-T(w)-b}{\gamma_{a}}\right]
$$

When the income tax function $T($.$) is differentiable with T^{\prime}() \leq$.1 everywhere, the solution to this program is unique and given by:

$$
w_{a}=\gamma_{a} \cdot a+\left(1-\gamma_{a}\right) \cdot\left(T\left(w_{a}\right)+b\right)
$$

Let $\tau_{a}=T\left(w_{a}\right)+b$ denote the employment tax for workers of skill $a$. Then

$$
w_{a}=\gamma_{a} \cdot a+\left(1-\gamma_{a}\right) \tau_{a}
$$

If the employment tax $\tau_{a}$ was exogenous, the gross wage $w_{a}$ would be increasing in $\tau_{a}$ : An increase in the employment tax reduces the employee's surplus hence the employee mitigates her loss by a larger bargained wage $w_{a}$. However, the employment tax is a function of the wage, $\tau_{a}=T\left(w_{a}\right)+b$. The following lemma solves this endogeneity issue.

Lemma 1 For any differentiable mapping $a \mapsto \tau_{a}$ such that

$$
-\frac{\gamma_{a}}{1-\gamma_{a}}-\frac{a-\tau_{a}}{1-\gamma_{a}} \frac{\partial \gamma_{a}}{\partial a}<\frac{\partial \tau_{a}}{\partial a}<1+\frac{a-\tau_{a}}{\gamma_{a}} \frac{\partial \gamma_{a}}{\partial a}
$$

There exists a single income tax function $w \mapsto T(w)$ such that employed workers of skill a receive the gross wage $w_{a}$ given by (7) and pay an amount of tax equal to $\tau_{a}-b$.

Proof. Given the mapping $a \mapsto \tau_{a}$, the wage given by (7) is increasing in $a$ only when the first inequality in (8) holds. In this case, Equation (7) can be inverted to express the skill $a$ as a differentiable function denoted $\mathcal{A}(w)$ of the wage. The income tax function has then to satisfy $T(w) \equiv \tau_{\mathcal{A}(w)}+b$, which implies:

$$
T^{\prime}(w)=\frac{\partial \tau_{a}}{\partial a} \mathcal{A}^{\prime}(w)=\frac{\frac{\partial \tau_{a}}{\partial a}}{\gamma_{a}+\left(1-\gamma_{a}\right) \frac{\partial \tau_{a}}{\partial a}+\left(a-\tau_{a}\right) \frac{\partial \gamma_{a}}{\partial a}}
$$

\footnotetext{
${ }^{8}$ L'Haridon, Malherbet and Perez-Duarte (2010) compare the properties of the Mortensen and Pissarides (1999) framework under three different solutions to the bargaining problem: The egalitarian, the Nash Bargaining and the Kalai-Smorodinsky solutions. When the worker and the firm have equal bargaining power (i.e. $\gamma=0.5$ ), our wage setting coincides with the "Egalitarian Solution" (see the derivation of their Equation (22)). The Nash solution conversely depends on the marginal tax rate. The Kalai-Smorodinsky solution depends on the level of $\operatorname{tax} T(a)$ in the utopian case where the worker extracts all the surplus.
} 
Under this tax function, Program (6) admits a single solution for $w_{a}$ if $T^{\prime}(w)<1$, which holds only if the second inequality in (8) holds.

According to this Lemma, under (8), the government's problem can be simplified as the design of an employment tax level for each skill level $a \mapsto \tau_{a}$. In the rest of this paper, we thus adopt a "relaxed" approach. We consider the design of a welfare benefit $b$ and an employment tax for each skill level $\tau_{a}$ that maximize the government's objective subject to the budget constraint. We consider only cases where the solution of this "relaxed" program verifies (8). This optimal allocation can then be decentralized by a tax schedule $w \mapsto T(w)$ that depends only on wages. This relaxed approach is similar in spirit to the first-order-approach adopted in the optimal intensive income tax literature (Mirrlees (1971)) when assuming the monotonicity constraint is slack (thus ruling out bunching). A similar simplification also holds in the optimal extensive income tax literature when the pooling issue is avoided ${ }^{9}$

Since $a-w_{a}=\left(1-\gamma_{a}\right)\left(a-\tau_{a}\right)$ from (7), the employment probability verifies:

$$
\ell_{a}=L_{a}\left[\left(1-\gamma_{a}\right)\left(a-\tau_{a}\right)\right]
$$

Combining (1) and (7), the expected surplus from participating equals:

$$
\Sigma_{a}=\gamma_{a} \cdot\left(a-\tau_{a}\right) \cdot L_{a}\left[\left(1-\gamma_{a}\right)\left(a-\tau_{a}\right)\right]
$$

and the skill-specific participation rate equals:

$$
h_{a}=H\left[\gamma_{a} \cdot\left(a-\tau_{a}\right) \cdot L_{a}\left[\left(1-\gamma_{a}\right)\left(a-\tau_{a}\right)\right] \mid a\right]
$$

Finally, the skill specific employment rate $e_{a}$ equals the product of the participation rate $h_{a}$ by the probability $\ell_{a}$ for each participant to find a job:

$$
e_{a}=\ell_{a} \cdot h_{a}=L_{a}\left[\left(1-\gamma_{a}\right)\left(a-\tau_{a}\right)\right] \cdot H\left[\gamma_{a}\left(a-\tau_{a}\right) L_{a}\left[\left(1-\gamma_{a}\right)\left(a-\tau_{a}\right)\right] \mid a\right]
$$

The employment rate responds to tax according to

$$
\frac{d e_{a}}{e_{a}}=-\left[\eta_{a}^{D}+\eta_{a}^{P}+\eta_{a}^{D} \eta_{a}^{P}\right] \frac{d \tau_{a}}{a-\tau_{a}}
$$

where we used elasticities defined in (3) and (5). We henceforth refer to the term in brackets in 13 as the global elasticity of employment. The product $\eta_{a}^{D} \eta_{a}^{P}$ enters this formula because any increase in the labor demand increases incentives to enter the labor force and hence reinforces the labor supply. This complementarity between labor demand and labor supply is a key insight of the unemployment matching theory.

\footnotetext{
${ }^{9}$ Choné and Laroque (2011) study conditions under which the pooling issue is avoided.
} 


\section{II.4 The government}

We assume that the government cares about the distribution of expected utilities, namely, $\ell_{a} \cdot\left(w_{a}-T\left(w_{a}\right)\right)+\left(1-\ell_{a}\right) \cdot b-\chi=\Sigma_{a}+b-\chi($ from (10) $)$ for those who participate and $b$ for nonparticipating individuals. More precisely, the government has the following Bergson-Samuelson social welfare function:

$$
\int_{a_{0}}^{a_{1}}\left\{\int_{0}^{\Sigma_{a}} \Phi\left(\Sigma_{a}+b-\chi\right) \cdot d H(\chi \mid a)+\Phi(b) \cdot\left(1-H\left(\Sigma_{a} \mid a\right)\right)\right\} d F(a)
$$

where $\Phi^{\prime}()>0,. \Phi^{\prime \prime}() \leq$.0 . The stronger the concavity of $\Phi($.$) the more averse to in-$ equality is the government. Assuming $\Phi^{\prime \prime}()=$.0 corresponds to the Benthamite Utilitarian criterion that sums the individual expected utilities.

The government faces the following budget constraint

$$
\int_{a_{0}}^{a_{1}} \tau_{a} \cdot e_{a} \cdot d F(a)-b-R=0
$$

that is written so that the welfare benefit $b$ is provided to all agents in the economy but for each additional worker of skill $a$, the government saves the welfare benefit $b$ and collects taxes $T\left(w_{a}\right)$ (the sum of these being $\tau_{a}$ ). Taking 12 into account, this budget constraint can be rewritten as

$$
\begin{aligned}
& \int_{a_{0}}^{a_{1}} \tau_{a} \cdot L_{a}\left[\left(1-\gamma_{a}\right)\left(a-\tau_{a}\right)\right] \cdot H\left(\gamma_{a} \cdot\left(a-\tau_{a}\right) \cdot L_{a}\left[\left(1-\gamma_{a}\right)\left(a-\tau_{a}\right)\right] \mid a\right) \cdot d F(a) \\
= & b+R
\end{aligned}
$$

\section{The optimal tax policy}

Following 1 , the optimal tax problem consists in finding the optimal level of benefit $b$ and employment tax levels $\tau_{a}$ that maximize the social objective (14) subject to the budget constraint (16), taking into (10) account. This problem is solved in Appendix $B$.

Let $\lambda$ be the Lagrange multiplier of the budget constraint. We interpret $\lambda$ as the marginal social cost of the public funds $R$. Let $g_{a}$ denote the marginal social welfare weight given to workers of skill $a$, expressed in terms of public funds, i.e.

$$
g_{a} \stackrel{\text { def }}{\equiv} \frac{\int_{0}^{\Sigma_{a}} \Phi^{\prime}\left(\Sigma_{a}+b-\chi\right) \cdot d H(\chi \mid a)}{\lambda \cdot h_{a}}
$$

Intuitively, the government is indifferent between giving one more euro to each participant of skill $a$ and giving $g_{a}$ euros of public funds. Symmetrically, we define

$$
g^{N} \stackrel{\text { def }}{\equiv} \frac{\Phi^{\prime}(b)}{\lambda}
$$

as the marginal social welfare weight of non-participating individuals expressed in terms of public funds. The optimal tax policy is given in the following proposition, which is proved in Appendix B and in the heuristic proof below. 
Proposition 1 For any skill level $a \in A$, the optimal tax schedule satisfies:

$$
\begin{gathered}
\int_{a_{0}}^{a_{1}}\left\{g_{a} \cdot h_{a}+g_{a}^{N} \cdot\left(1-h_{a}\right)\right\} \cdot d F(a)=1 \\
\frac{\tau_{a}}{w_{a}-\tau_{a}}=\frac{1-g_{a} \cdot \gamma_{a} \cdot\left(1+\eta_{a}^{D}\right)}{\gamma_{a} \cdot\left[\eta_{a}^{D}+\eta_{a}^{P}+\eta_{a}^{D} \eta_{a}^{P}\right]}
\end{gathered}
$$

or

$$
\tau_{a}=\frac{1-g_{a} \cdot \gamma_{a} \cdot\left(1+\eta_{a}^{D}\right)}{1-g_{a} \cdot \gamma_{a} \cdot\left(1+\eta_{a}^{D}\right)+\gamma_{a} \cdot\left[\eta_{a}^{D}+\eta_{a}^{P}+\eta_{a}^{D} \eta_{a}^{P}\right]} w_{a}
$$

or

$$
\tau_{a}=\frac{1-g_{a} \cdot \gamma_{a} \cdot\left(1+\eta_{a}^{D}\right)}{1-g_{a} \cdot \gamma_{a} \cdot\left(1+\eta_{a}^{D}\right)+\eta_{a}^{D}+\eta_{a}^{P}+\eta_{a}^{D} \eta_{a}^{P}} a
$$

Equation (19a) states that the marginal cost of public funds is a weighted average of the social marginal utilities of the workers $\left(g_{a}\right)$ and of the unemployed $\left(g_{a}^{N}\right)$. Equation (19b) states that the optimal employment tax rate is an inverse elasticity rule: The larger the global elasticity of employment $\eta_{a}^{D}+\eta_{a}^{P}+\eta_{a}^{D} \eta_{a}^{P}$, the lower the absolute value of the employment tax rate. Using $w_{a}-\tau_{a}=\gamma_{a}\left(a-\tau_{a}\right),(19 \mathrm{~b})$ can be rewritten as $\tau_{a} /\left(a-\tau_{a}\right)=$ $\left[1-g_{a} \cdot \gamma_{a} \cdot\left(1+\eta_{a}^{D}\right)\right] /\left[\eta_{a}^{D}+\eta_{a}^{P}+\eta_{a}^{D} \eta_{a}^{P}\right]$ so that $\gamma_{a}$ does not appear anymore in the denominator of our inverse elasticity rule. Equation $19 \mathrm{~b}$ leads to 20 .

Our general model encompasses two specific cases. First, one can retrieve the pure extensive margin model when the matching function verifies $M_{a}(V, U)=U$ and $\gamma_{a}=1$. When $M_{a}(V, U)=U$, any job-seeker becomes employed, as in Diamond (1980), Saez (2002) and Choné and Laroque $(2005,2011)$ and $\eta_{a}^{D}=0$. When $\gamma_{a}=1$, Equation (7) leads to the equality between the gross wage $w_{a}$ and the marginal product $a$. Under these two assumptions, to which we henceforth refer to as the "pure extensive response" model, Equation $19 \mathrm{~b}$ becomes identical to the inverse elasticity rule of Saez (2002) in the absence of intensive response, i.e.

$$
\frac{\tau_{a}}{w_{a}-\tau_{a}}=\frac{1-g_{a}}{\eta_{a}^{P}}
$$

where $\eta_{a}^{P}$ measures here the elasticity of participation with respect to $w_{a}-\tau_{a}$.

Second, our model also encompasses the polar "pure labor demand response" model with full participation decisions where $h_{a}=1$ and $\eta_{a}^{P}=0$. Equations $19 \mathrm{a}-1 \mathrm{~b}$ ) then become:

$$
\begin{gathered}
\int_{a_{0}}^{a_{1}} g_{a} \cdot d F(a)=1 \\
\frac{\tau_{a}}{w_{a}-\tau_{a}}=\frac{1-g_{a} \cdot \gamma_{a} \cdot\left(1+\eta_{a}^{D}\right)}{\gamma_{a} \cdot \eta_{a}^{D}} \Leftrightarrow \frac{\tau_{a}}{a-\tau_{a}}=\frac{1-g_{a} \cdot \gamma_{a} \cdot\left(1+\eta_{a}^{D}\right)}{\eta_{a}^{D}}
\end{gathered}
$$

In the "pure labor demand response", the optimal employment tax also follows an inverse elasticity rule but the only responses that prevail are the ones from the labor demand side 
through $\eta_{a}^{D}$. The intuition behind the numerator of $23 \mathrm{~b}$ will be provided in the heuristic proof below.

\section{III.1 Heuristic proof}

To derive and interpret Equations (19b), (22) and (23b), we consider a perturbation of the optimal tax function that consists in a small increas ${ }^{10} d T\left(w_{a}\right)>0$ of the tax liability at wage $w_{a}$. For a constant level of benefit $b$, this increase induces a rise $d \tau_{a}=d T\left(w_{a}\right)$ in the employment tax $\tau_{a}$ paid by workers of skill level, which implies a "mechanical" effect, an "employment response" effect and a "social welfare" effect that we now describe.

\section{Mechanical effect}

Absent any behavioral change, the government levies $d \tau_{a}$ additional taxes on each job of skill $a$. As only a fraction $e_{a}$ of individuals of skill $a$ are employed, the mechanical increase in tax revenue per individual of skill $a$ equals:

$$
\mathcal{M}_{a}=e_{a} \cdot d \tau_{a}
$$

This effect is identical in our general model, in the pure extensive case and in the pure labor demand case.

\section{Employment response effect}

The increase in the employment tax induces a reduction in the employment rate $e_{a}=$ $\ell_{a} h_{a}$ that is given by (13). Using (7), employment changes by:

$$
d e_{a}=-\gamma_{a} \cdot\left[\eta_{a}^{D}+\eta_{a}^{P}+\eta_{a}^{D} \eta_{a}^{P}\right] \cdot \frac{d \tau_{a}}{w_{a}-\tau_{a}} \cdot e_{a}
$$

This reduction is made of a direct change in participation, a direct labor demand response and the effect of the labor demand response on the incentives to participate. In particular, the term $\eta_{a}^{D} \eta_{a}^{P}$ captures the complementarity between labor demand and participation responses: Any increase in the labor demand reinforces incentives to enter the labor force and hence boosts the labor supply. The bargaining power $\gamma_{a}$ appears because we express the optimal level of the employment tax as a fraction of the gross wage level $w_{a}$. This parameter would have been absent if instead we had written the employment tax as a fraction of the skill level $a{ }^{11}$ As each additional worker of skill $a$ increases the government's revenue by the employment tax $\tau_{a}$, the employment effect per individual of skill $a$ equals

$$
\mathcal{E}_{a}=-\gamma_{a} \cdot\left[\eta_{a}^{D}+\eta_{a}^{P}+\eta_{a}^{D} \eta_{a}^{P}\right] \cdot \frac{\tau_{a}}{w_{a}-\tau_{a}} \cdot e_{a} \cdot d \tau_{a}
$$

\footnotetext{
${ }^{10}$ The case where the employment tax decreases is symmetric as only first-order effects are considered.

${ }^{11}$ As $w_{a}-\tau_{a}=\gamma_{a}\left(a-\tau_{a}\right)$ from $(7)$, we would have instead $d_{e}=\left[\eta_{a}^{D}+\eta_{a}^{P}+\eta_{a}^{D} \cdot \eta_{a}^{P}\right] \cdot \frac{d w_{a}}{a-\tau_{a}} \cdot e_{a}$
} 
There are two differences with the pure extensive case. First, the global elasticity of employment $\eta_{a}^{D}+\eta_{a}^{P}+\eta_{a}^{D} \eta_{a}^{P}$ matters instead of the sole labor supply elasticity $\eta_{a}^{P}$. Second, the employment response effect is multiplied by the fraction $\gamma_{a}$ of the surplus that accrues to the worker. In the pure extensive case, one has $\gamma_{a}=1$ and $w_{a}=a 2^{12}$

In the pure labor demand response case, the global elasticity of employment $\eta_{a}^{D}+$ $\eta_{a}^{P}+\eta_{a}^{D} \eta_{a}^{P}$ is reduced to the sole labor demand elasticity $\eta_{a}^{D}$ since only the labor demand response prevails ${ }^{13}$

\section{Social welfare effect}

We now describe how the reform affects the social welfare function (14). Given our assumption that the government cares about the distribution of expected utilities, one should determine how the reform modifies the expected surplus $\Sigma_{a}$ defined in (1). On the one hand, there is a direct effect on the surplus $w_{a}-\tau_{a}$ extracted by the worker. From (7), this change amounts to

$$
d\left(w_{a}-\tau_{a}\right)=-\gamma_{a} \cdot d \tau_{a}
$$

On the other hand, the labor demand response implies a reduction in the job-finding probability $\ell_{a}$. From (5) and (9), this term equals

$$
d \ell_{a}=-\eta_{a}^{D} \cdot \frac{1}{a-\tau_{a}} \cdot \ell_{a} \cdot d \tau_{a}
$$

Combining these two effects, the expected surplus is reduced by

$$
d \Sigma_{a}=-\gamma_{a} \cdot\left(1+\eta_{a}^{D}\right) \cdot \ell_{a} \cdot d \tau_{a}
$$

This reduction induces some individuals to stop participating. However, these pivotal individuals are indifferent between participating or not, so the change in their participation decisions has no first-order effect on the social objective. Recall that $g_{a}$ is the marginal social welfare weight given to workers of skill $a$, expressed in terms of public funds (see (17)). The social welfare effect per individual of skill $a$ equals:

$$
\mathcal{W}_{a}=-g_{a} \cdot \gamma_{a}\left(1+\eta_{a}^{D}\right) \cdot e_{a} \cdot d \tau_{a}
$$

\footnotetext{
${ }^{12}$ The above distinction between expressing the employment tax as a fraction of the wage or as a fraction of the skill becomes meaningless.

${ }^{13}$ Appendix $C$ considers the optimal tax problem when the government observes also the cost of searching $\chi$. The optimal employment tax is then inversely related to the labor demand elasticity only. Intuitively, in such a case, the government can condition taxation on the cost of searching to enforce individuals' participation decisions without distorting labor supply. The labor supply elasticity then does not appear in the optimal tax formula. However, the labor demand elasticity remains for two reasons. First, the government cannot influence the matching process. Second, the government has no tax instrument to influence the number of vacancies created on each labor market.
} 
In the pure extensive response model where $\gamma_{a}=1$ and $\eta_{a}^{D}=0$, the term $\gamma_{a}\left(1+\eta_{a}^{D}\right)$ of the welfare effect 26 simplifies to 1 . In the general model, the term $\gamma_{a}\left(1+\eta_{a}^{D}\right)$ equals 1 only when:

$$
\frac{1-\gamma_{a}}{\gamma_{a}}=\eta_{a}^{D}
$$

From (5), this restriction amounts to the equality between the worker's share $\gamma_{a}$ of the total surplus and the elasticity $\mu_{a}$ of the matching function with respect to unemployment. This equality is known in the matching literature as the Hosios (1990) condition. In an economy without taxes and transfers, it ensures that the total surplus generated by a match is shared in such a way that the congestion externalities are internalized. There is no particular reason why the Hosios condition should be satisfied, since it "relates a parameter of the resolution of bargaining conflict to a parameter of the technology of matching" (Pissarides (2000, page 198)).

In our model, when the Hosios condition (27) is not met, the tax instrument cannot be used to correct for congestion externalities, as it cannot modify the fraction of the surplus that each party receives through the wage bargain. Still, a deviation from the Hosios condition affects the optimal tax for tax incidence reasons. Workers only pay a fraction $\gamma_{a}$ of a tax increase from (7). The latter affects the expected surplus through a direct effect on net earnings and an indirect one on the probability of finding a job. The term $\gamma_{a}\left(1+\eta_{a}^{D}\right)$ therefore captures the incidence of a tax increase on the welfare of a participant of skill $a$.

A small change in the employment tax must imply no first-order effect. Adding (24), (25) and (26) and rearranging terms gives (19b). Rearranging terms again lead to the optimal employment tax rates given in 20 .

\section{III.2 Sign of the optimal employment tax}

The sign of the employment tax rate is given by the difference between the mechanical (24) and the social welfare effects (26). Therefore, as shown by (19b), the employment tax is positive for workers whose weights $g_{a}$ are lower than $1 /\left[\gamma_{a}\left(1+\eta_{a}^{D}\right)\right]$ and negative for the others.

In the pure labor demand case, the weighted average of social welfare weights $\int_{a_{0}}^{a_{1}} g_{a}$. $d F(a)$ equals 1 (see (23a)). Under a concave social welfare function $\Phi($.$) , the social$ welfare weights $g_{a}$ are decreasing in the skill levels $a$ under the plausible assumption that the expected surplus $\Sigma_{a}$ is increasing in the skill level. Therefore, if one also assumes that the Hosios condition (27) holds, the employment tax on the least skilled workers is negative, a case that Saez (2002) defines as an Earned Income Tax Credit (EITC). 
In the pure extensive case and in the general model, the welfare of nonparticipants has to be taken into account. From (17) and (18), one has $g_{N}>g_{a}$ whenever the social welfare function $\Phi($.$) is concave. In particular, when the social welfare function is close$ to a Maximin objective, one typically obtains $g^{N}>1>g_{a}$. If the Hosios condition holds in the general model, an EITC is then ruled out, since the numerator of $(19 \mathrm{~b})$ simplifies to $1-g_{a}$.

\section{III.3 Quantitative insights}

In this section, we numerically investigate how introducing the labor demand response affects the optimal employment tax rates $\tau_{a} / w_{a}$. For this purpose, we use (20) to compute optimal employment tax rates for different calibrated values of $\eta_{a}^{P}, \eta_{a}^{D}, \gamma_{a}$ and $g_{a}$.

We take three values for $\eta_{a}^{P}$, namely $0,0.25$, and 0.5 . These values are plausible lower bound, average and higher bound estimates for $\eta_{a}^{P}$, according to Immervoll et alii (2007) and Meghir and Phillips (2008), among others. To calibrate the elasticity $\eta_{a}^{D}$ of the jobfinding probability with respect to the firm surplus $a-w_{a}$, we use (5) and the estimates of the matching function surveyed by Petrongolo and Pissarides (2001). We take $\mu=0.5$, thereby $\eta_{a}^{D}=1$ as a benchmark. However, we also consider the pure extensive case where the labor demand is unresponsive $\left(\eta_{a}^{D}=0\right)$ and an intermediate case, namely $\eta_{a}^{D}=0.5$.

\begin{tabular}{|l||c|c|c|c|c|c|}
\hline \multicolumn{1}{|r||}{$g_{a}$} & \multicolumn{3}{c|}{0} & \multicolumn{3}{c|}{0.5} \\
\hline$\eta_{a}^{D}$ & 0 & 0.5 & 1 & 0 & 0.5 & 1 \\
\hline$\eta_{a}^{P} \gamma_{a}$ & 1 & $2 / 3$ & 0.5 & 1 & $2 / 3$ & 0.5 \\
\hline \hline 0 & & & & & & \\
\hline 0.25 & $80.0 \%$ & $63.2 \%$ & $57.1 \%$ & $66.7 \%$ & $46.2 \%$ & $40.0 \%$ \\
\hline 0.5 & $66.7 \%$ & $54.5 \%$ & $50.0 \%$ & $50.0 \%$ & $37.5 \%$ & $33.3 \%$ \\
\hline
\end{tabular}

Table 1: Optimal employment taxes $\tau_{a} / w_{a}$ under the Hosios condition

We consider in Table 1 cases where the bargaining power is adjusted to fulfill the Hosios condition (27). Hence $\gamma_{a} \cdot\left(1+\eta_{a}^{D}\right)$ remains equal to 1 . The first and fourth columns give $\tau_{a} / w_{a}$ in the pure extensive response model (where $\eta_{a}^{D}=0$ ) while the first row provides values of $\tau_{a} / w_{a}$ in the pure labor demand model (where $\eta_{a}^{P}=0$ ). Increasing the labor demand elasticity implies two effects on the optimal employment tax rates. First, the global elasticity of employment $\eta_{a}^{D}+\eta_{a}^{P}+\eta_{a}^{D} \eta_{a}^{P}$ increases, which tends to reduce the magnitude of the employment tax rates. Second, according to 21, the reduction in $\gamma_{a}$ that takes place to keep the Hosios condition does not change the ratio of the optimal employment tax $\tau_{a}$ to the skill level $a$. However, it reduces the ratio of the wage $w_{a}$ to the skill $a$, hence it tends to increase the employment tax rate $\tau_{a} / w_{a}$. The overall effect is 
negative under the Hosios condition 14 This effect is quantified in Table 1. A larger labor demand elasticity substantially reduces the optimal employment tax. For instance, when $\eta_{a}^{P}=0.25, \tau_{a} / w_{a}$ shrinks by 23 percentage points (from $80 \%$ to $57 \%$ ) under Maximin and by 33 percentage points (from $67 \%$ to $40 \%$ ) with a marginal social welfare weight $g_{a}$ equals to 0.5 .

\begin{tabular}{|c|c|c|c|c|c|c|}
\hline & \multicolumn{3}{|c|}{0} & \multicolumn{3}{|c|}{0.5} \\
\hline & 0 & 0.5 & 1 & 0 & 0.5 & 1 \\
\hline$\eta_{a}^{D}+\eta_{a}^{P}+\eta_{a}^{D} \eta_{a}^{P}$ & 1 & $2 / 3$ & 0.5 & 1 & $2 / 3$ & 0.5 \\
\hline 0.5 & $66.7 \%$ & $75.0 \%$ & $x$ & $50.0 \%$ & $60.0 \%$ & $x$ \\
\hline 0.75 & $57.1 \%$ & $66.7 \%$ & $x$ & $40.0 \%$ & $50.0 \%$ & $x$ \\
\hline 1 & $50.0 \%$ & $60.0 \%$ & $66.7 \%$ & $33.3 \%$ & $42.9 \%$ & $50.0 \%$ \\
\hline
\end{tabular}

Table 2: Optimal employment taxes $\tau_{a} / w_{a}$ under the Hosios condition

The empirical literature on labor taxation typically distinguishes an intensive margin and an extensive margin of the labor supply. In estimating the latter, the controls for changes in job-finding probabilities are typically lacking. Hence, it is unclear whether the responses of employment to taxation identify the sole participation elasticity $\eta_{a}^{P}$, or the global employment elasticity $\eta_{a}^{D}+\eta_{a}^{P}+\eta_{a}^{D} \eta_{a}^{P}$. Consequently, in each row of Table 2 , the global elasticity of employment remains constant (at respectively 0.5, 0.7 and 1). As the labor demand elasticity increases, the participation elasticity shrinks. Some cells in Table 2 are empty since $\eta_{a}^{P}$ cannot be negative. Moreover, the bargaining power $\gamma_{a}$ is again adjusted to fulfill the Hosios condition 27). Increasing $\eta_{a}^{D}$ requires to reduce $\gamma_{a}$ to keep the Hosios condition satisfied. Therefore, from with $g_{a}<1$, the optimal employment tax rate increase with $\eta_{a}^{D}$, the global elasticity being constant. Increasing $\eta_{a}^{D}$ from 0 to 0.5 increases the employment tax $\tau_{a}$ by about 8 or 10 percentage points when $g_{a}=0$. Employment tax rates are lower when $g_{a}=0.5$ and increase in $\eta_{a}^{D}$ by a similar extent. Hence, for a given global elasticity of employment, optimal employment tax rates are substantially higher when labor demand responses contribute more (thereby participation responses contribute less) to the global elasticity of employment.

Finally, Table 3 studies the impact of deviating from the Hosios condition (27). In each row, we vary the worker's share $\gamma_{a}$ of the total surplus, while we keep $\eta_{a}^{D}$ at its benchmark value of 1. A low $\left(\gamma_{a}=0.3\right)$ and a high $\left(\gamma_{a}=0.7\right)$ value are taken to illustrate the

\footnotetext{
${ }^{14}$ Under the Hosios condition $\sqrt{27}$, Equation 20 simplifies to

$$
\frac{\tau_{a}}{w_{a}}=\frac{1-g_{a}}{1-g_{a}+\gamma \cdot\left[\left(1+\eta_{a}^{D}\right)\left(1+\eta_{a}^{P}\right)-1\right]}=\frac{1-g_{a}}{1-g_{a}+1+\eta_{a}^{P}-\frac{1}{1+\eta_{a}^{D}}}
$$
}

where we use again the Hosios condition 27 to get the second equality. Hence, optimal employment tax rates in absolute value decreases with the labor demand elasticity. 


\begin{tabular}{|c|c|c|c|c|c|c|}
\hline$g_{a}$ & \multicolumn{3}{|c|}{0} & \multicolumn{3}{|c|}{0.5} \\
\hline$\eta_{a}^{D}$ & \multicolumn{3}{|c|}{1} & \multicolumn{3}{|c|}{1} \\
\hline$\eta_{a}^{P}{ }^{\gamma_{a}}$ & 0.3 & 0.5 & 0.7 & 0.3 & 0.5 & 0.7 \\
\hline 0 & $76.9 \%$ & $66.7 \%$ & $58.8 \%$ & $70.0 \%$ & $50.0 \%$ & $30.0 \%$ \\
\hline 0.25 & $69.0 \%$ & $57.1 \%$ & $48.8 \%$ & $60.9 \%$ & $40.0 \%$ & $22.2 \%$ \\
\hline 0.5 & $62.5 \%$ & $50.0 \%$ & $41.7 \%$ & $53.8 \%$ & $33.3 \%$ & $17.6 \%$ \\
\hline
\end{tabular}

Table 3: Optimal employment tax rates $\tau_{a} / w_{a}$ when the Hosios condition is violated

consequences of a deviation from the Hosios condition (the central value being $\gamma_{a}=0.5$ ). According to $19 \mathrm{~b}$, a rise in $\gamma_{a}$ has two effects on the optimal employment tax rate $\tau_{a} / w_{a}$. First, the employment tax rate is the product of the ratio of the employment tax to the skill level $\tau_{a} / a$ times the ratio of the skill level to the gross wage $a / w_{a}$. When $g_{a}=0$, the first term is unaffected by a rise in $\gamma_{a}$, while the second shrinks. Hence the optimal employment tax rate decreases when $g_{a}=0$. Second, a given increase of the employment $\operatorname{tax} \tau_{a}$ has a larger impact on the welfare of the workers when $\gamma_{a}$ is higher. Therefore, the optimal employment tax decreases with $\gamma_{a}$. Table 3 highlights that the quantitative impact of $\gamma_{a}$ is substantial. For instance, when $g_{a}=0$, increasing the worker's share $\gamma_{a}$ from 0.3 to 0.7 reduces the optimal employment tax rate by approximately one third. When $\eta_{a}^{P}=0.25$ and $g_{a}=0.5$, increasing $\gamma_{a}$ from 0.3 to 0.7 divides the employment tax rate by nearly 3 .

\section{Conclusion}

The optimal tax schedule derived in the optimal tax model with labor supply along the extensive margin is drastically modified when labor demand is taken into account in a search-matching economy. The employment tax is still an inverse elasticity rule however the elasticity term encapsulates not only labor supply responses (as in the standard model) but also labor demand responses and the interaction effects between labor demand and labor supply, the latter two being neglected in the standard framework. For plausible values of the parameters, matching frictions induce much lower employment tax rates than the ones found in the usual competitive model with endogenous participation decisions.

\section{References}

[1] Allen, S. (1987), Taxation, redistribution, and the minimum wage: a theoretical analysis, Quarterly Journal of Economics, 101, 477-489. 
[2] Beaudry, P., Green, D. and B. Sand (2010), How much Is Employment Increased by Cutting Labor Costs? Estimating the Elasticity of Job Creation, NBER Working Paper 15790.

[3] Boadway R., Cuff K. and N. Marceau (2003), Redistribution and employment policies with endogenous unemployment, Journal of Public Economics, 87, 2407- 2430.

[4] Boone, J. and L. Bovenberg (2002), Optimal labour taxation and search, Journal of Public Economics, 85, 53-97.

[5] Choné, P. and G. Laroque (2005), Optimal Incentives for Labor Force Participation, Journal of Public Economics, 89 (2-3), 395-425.

[6] Choné, P. and G. Laroque (2011), Optimal Taxation in the Extensive Model, Journal of Economic Theory, Forthcoming.

[7] Diamond P. (1980), Income Taxation with Fixed Hours of Work, Journal of Public Economics, 13, 101-110.

[8] Diamond P. and E. Sheshinski (1996), Economic Aspects of Optimal Disability Benefits, Journal of Public Economic Theory, 57, 1-23.

[9] Guesneries, R. and K. Roberts (1984), "Effective Policy Tools and Quantity Controls", Econometrica, 52(1), 59-86.

[10] Guesneries, R. and K. Roberts (1987), "Minimum wage legislation as a second best policy", European Economic Review, 31, 490-498.

[11] Hosios, A. (1990), On the Efficiency of Matching and Related Models of Search and Unemployment, Review of Economic Studies, 57, 279-298.

[12] Hungerbühler, M., Lehmann, E. (2009), On the Optimality of a Minimum Wage: New Insights from Optimal Tax Theory, Journal of Public Economics, 93 (3-4), 464-481

[13] Hungerbühler, M., Lehmann, E., Parmentier, A. and B. Van der Linden (2006), Optimal Redistributive Taxation in a Search Equilibrium Model, Review of Economic Studies, 2006, 73 (3), 743-768.

[14] Immervoll, H., Kleven, H., Kreiner, C. T. and Saez, E., 2007, Welfare reforms in European countries: a Microsimulation analysis, Economic Journal, 117, 1-44.

[15] Kramarz, F. and T. Philippon (2001), The impact of differential payroll tax subsidies on minimum wage employment, Journal of Public Economics, 82, 115-146. 
[16] Lee, D. and E. Saez (2008), "Optimal Minimum Wage in Competitive Labor Markets", NBER Working Paper, $\mathrm{N}^{\circ} 14320$.

[17] Lehmann, E., Parmentier, A. and B. Van der Linden (2011), Optimal income taxation with endogenous participation and search unemployment, CESifo Discussion Paper 3324.

[18] L'Haridon, O., F. Malherbet, S. Perez-Duarte, 2010, Does Bargaining Matter in the Small Firm Matching Model?, IZA Discusssion Paper Series, $\mathrm{N}^{\circ} 5181$.

[19] Meghir, C. and D. Phillips (2008), Labour supply and taxes, IZA Discusssion Paper Series, $\mathrm{N}^{\circ} 3405$.

[20] Mirrlees, J. (1971), An Exploration in the Theory of Optimum Income Taxation, Review of Economic Studies, 38(2), 175-208.

[21] Mortensen, D. and Pissarides, C. (1999), New developments in models of search in the Labor Market, in O. Ashenfelter and D. Card (eds.), Handbook of Labor Economics, vol 3, B, North-Holland, Amsterdam.

[22] Petrongolo, B. and Pissarides, C.A. (2001), Looking into the black box: a survey of the matching function, Journal of Economic Literature, 39, 716-741.

[23] Pissarides, C. A (2000), Equilibrium Unemployment Theory, $2^{\text {nd }}$ Edition, Cambridge: MIT Press.

[24] Saez, E. (2002), Optimal Income Transfer Programs:Intensive Versus Extensive Labor Supply Responses, Quarterly Journal of Economics, 117, 1039-1073.

[25] Stiglitz, J.E. (1982), "Self-selection and Pareto efficient taxation," Journal of Public Economics, 17(2), 213-240,

\section{Appendices}

\section{A Link between the elasticity of the labor demand and the elasticity of the matching function}

Let $\mu_{a}($.$) denote the elasticity of the matching function M_{a}(.,$.$) with respect to the mass$ of job-seekers $U_{a}$. Because the matching function is increasing in both arguments and exhibits constant returns to scale, $\mu_{a}$ depends only on the level of tightness and one has $\mu_{a}(\theta) \in(0,1)$ for all $\theta$. From $m_{a}(\theta)=M_{a}(1,1 / \theta)$, the elasticity of the probability of filling a vacancy to the tightness level (i.e. $\left.\left(\theta_{a} / m_{a}\right)\left(\partial m_{a}(\theta) / \partial \theta_{a}\right)\right)$ equals $-\mu_{a}(\theta)$. Hence 
the elasticity of the reciprocal $m_{a}^{-1}($.$) equals -1 / \mu_{a}\left(m_{a}^{-1}().\right)$. The log-differentiation of the $L_{a}$ function (4) with respect to the firm's surplus $a-w_{a}$ gives:

$$
\frac{d L_{a}}{L_{a}}=\left(-1+\frac{1}{\mu_{a}\left(\theta_{a}\right)}\right) \cdot \frac{d\left(a-w_{a}\right)}{a-w_{a}}
$$

which leads to the second equality in (5). The inequality holds because $\mu_{a}(\theta) \in(0,1)$.

\section{B Proof of Proposition 1}

The Lagrangian of the optimal tax problem is

$$
\int_{a_{0}}^{a_{1}} \mathcal{L}\left(\tau_{a}, b, \lambda\right) \cdot d F(a)-\lambda b-\lambda R
$$

where

$$
\begin{gathered}
\mathcal{L}\left(\tau_{a}, b, \lambda\right) \stackrel{\text { def }}{\equiv} \int_{0}^{\gamma_{a} \cdot\left(a-\tau_{a}\right) \cdot L_{a}\left[\left(1-\gamma_{a}\right)\left(a-\tau_{a}\right)\right]} \Phi\left(\gamma_{a} \cdot\left(a-\tau_{a}\right) \cdot L_{a}\left[\left(1-\gamma_{a}\right)\left(a-\tau_{a}\right)\right]+b-\chi\right) \cdot d H(\chi \mid a) \\
+\Phi(b) \cdot\left(1-H\left(\gamma_{a} \cdot\left(a-\tau_{a}\right) \cdot L_{a}\left[\left(1-\gamma_{a}\right)\left(a-\tau_{a}\right)\right] \mid a\right)\right) \\
+\lambda \cdot \tau_{a} \cdot L_{a}\left[\left(1-\gamma_{a}\right)\left(a-\tau_{a}\right)\right] \cdot H\left(\gamma_{a} \cdot\left(a-\tau_{a}\right) \cdot L_{a}\left[\left(1-\gamma_{a}\right)\left(a-\tau_{a}\right)\right] \mid a\right)
\end{gathered}
$$

The first-order condition with respect to $b$ is:

$\int_{a_{0}}^{a_{1}}\left\{\int_{0}^{\gamma_{a} \cdot\left(a-\tau_{a}\right) \cdot L_{a}\left[\left(1-\gamma_{a}\right)\left(a-\tau_{a}\right)\right]} \Phi^{\prime}\left(\Sigma_{a}+b-\chi\right) \cdot d H(\chi \mid a)+\Phi^{\prime}(b) \cdot\left(1-h_{a}\right)\right\} d F(a)=\lambda$

Using (17) and (18) gives (19a). The first-order condition with respect to $\tau_{a}$ writes $0=$ $\frac{\partial \mathcal{L}}{\partial \tau_{a}}\left(\tau_{a}, b, \lambda\right)$. Using (3) and (5), this leads to:

$$
\begin{aligned}
0= & -\gamma_{a} \cdot\left(1+\eta_{a}^{D}\right) \cdot \ell_{a} \cdot\left(\int_{0}^{\Sigma_{a}} \Phi^{\prime}\left(\Sigma_{a}+b-\chi\right) \cdot d H(\chi \mid a)\right) \\
& +\lambda\left\{1-\frac{\tau_{a}}{a-\tau_{a}} \eta_{a}^{D}-\frac{\tau_{a}}{a-\tau_{a}}\left(1+\eta_{a}^{D}\right) \cdot \eta_{a}^{P}\right\} \ell_{a} \cdot h_{a}
\end{aligned}
$$

Dividing both sides by $\lambda h_{a} \ell_{a}=\lambda e_{a}$, using (17) and $w_{a}-\tau_{a}=\gamma_{a}\left(a-\tau_{a}\right)$ (from (7)) gives 19b.

\section{The government observes $(a, \chi)$}

This appendix derives the optimal tax schedule when the government observes individuals' characteristics $(a, \chi)$ but not their search activity. In this framework, the utility of agents who do not search for a job is $b_{a, \chi}$, the utility of those who search but do not find a job is $b_{a, \chi}-\chi$ while those who obtain a job obtain $w_{a, \chi}-\tau_{a, \chi}+b_{a, \chi}-\chi$. The worker's surplus is then $w_{a, \chi}-\tau_{a, \chi}$ and the firm's surplus is $a-w_{a, \chi}$. The bargained wage (7) becomes

$$
w_{a, \chi}=\gamma_{a} \cdot a+\left(1-\gamma_{a}\right) \tau_{a, \chi}
$$


hence the probability of having a job for a participating individual states as $\ell_{a, \chi}=$ $L_{a}\left[\left(1-\gamma_{a}\right)\left(a-\tau_{a, \chi}\right)\right]$. This allows to write the participation constraints as

$$
L_{a}\left[\left(1-\gamma_{a}\right)\left(a-\tau_{a, \chi}\right)\right] \cdot \gamma_{a} \cdot\left(a-\tau_{a, \chi}\right) \geq \chi
$$

We denote $\mathbb{I}_{a, \chi}=1$ when this constraint is satisfied and $\mathbb{I}_{a, \chi}=0$ otherwise. This allows to write the budget constraint as

$$
R=\iint\left\langle\tau_{a, \chi} \cdot \mathbb{I}_{a, \chi} \cdot L_{a}\left[\left(1-\gamma_{a}\right)\left(a-\tau_{a, \chi}\right)\right]-b_{a, \chi}\right\rangle d H(\chi \mid a) d F(a)
$$

and we denote $\lambda \geq 0$ the Lagrangian multiplier associated to this constraint. The Lagrangian can be formulated as

$$
\begin{gathered}
\mathcal{L}=\iint\left\langle\mathbb{I}_{a, \chi} \cdot \Phi\left[\gamma_{a} \cdot\left(a-\tau_{a, \chi}\right) \cdot L_{a}\left[\left(1-\gamma_{a}\right)\left(a-\tau_{a, \chi}\right)\right]+b_{a, \chi}-\chi\right]+\left(1-\mathbb{I}_{a, \chi}\right) \cdot \Phi\left[b_{a, \chi}\right]\right. \\
\left.+\lambda \cdot\left\{\mathbb{I}_{a, \chi} \cdot L_{a}\left[\left(1-\gamma_{a}\right)\left(a-\tau_{a, \chi}\right)\right] \cdot \tau_{a, \chi}-b_{a, \chi}\right\}\right\rangle d H(\chi \mid a) d F(a)
\end{gathered}
$$

First, we state the first-order condition for people who participate and next for nonparticipants. If $\mathbb{I}_{a, \chi}=1$, the first-order condition with respect to $\tau_{a, \chi}$ is:

$$
\left\{L_{a}[.]+\left(1-\gamma_{a}\right) \cdot\left(a-\tau_{a, \chi}\right) \cdot L_{a}^{\prime}[.]\right\} \cdot \gamma_{a} \cdot \frac{\Phi^{\prime}[.]}{\lambda}=\left\{L_{a}[.]-\left(1-\gamma_{a}\right) \cdot \tau_{a, \chi} \cdot L_{a}^{\prime}\right\}
$$

Using (5) and simplifying by $L_{a}[$.$] , we obtain:$

$$
\frac{\tau_{a, \chi}}{a-\tau_{a, \chi}}=\frac{1-\left(1+\eta_{a}^{D}\right) \cdot \gamma_{a} \cdot \frac{\Phi^{\prime}[\cdot]}{\lambda}}{\eta_{a}^{D}}
$$

which is equivalent to $23 \mathrm{~b}$ except that $\Phi^{\prime}[.] / \lambda$ stands instead of $g_{a}$. The first-order condition with respect to $b_{a, \chi}$ is:

$$
\mathbb{I}_{a, \chi} \cdot \Phi^{\prime}\left[\gamma_{a} \cdot\left(a-\tau_{a, \chi}\right) \cdot L_{a}\left[\left(1-\gamma_{a}\right)\left(a-\tau_{a, \chi}\right)\right]+b_{a, \chi}-\chi\right]+\left(1-\mathbb{I}_{a, \chi}\right) \Phi^{\prime}\left[b_{a, \chi}\right]=\lambda
$$

This condition implies that all expected utilities are equalized across individuals, whatever their participation decision. Denote $z$ the common value for the expected utilities, with $\Phi^{\prime}[z]=\lambda$. The expected utility of people of type $(a, \chi)$ is

$$
\ell_{a, \chi}\left(w_{a, \chi}-\tau_{a, \chi}\right)+b_{a, \chi}-\chi=z
$$

The optimality condition with respect to $\mathbb{I}_{a, \chi}$ implies that individuals of type $(a, \chi)$ participate if and only if:

$$
\ell_{a, \chi} \cdot \tau_{a, \chi} \geq 0
$$

which can be rewritten, using (30), as:

$$
\ell_{a, \chi} \cdot w_{a, \chi} \geq \chi+z-b_{a, \chi}
$$

Finally, equation (29) allows to rewrite $(28)$ as

$$
\frac{\tau_{a, \chi}}{a-\tau_{a, \chi}}=\frac{1-\left(1+\eta_{a}^{D}\right) \cdot \gamma_{a}}{\eta_{a}^{D}}
$$

